Bedankt voor het downloaden van dit artikel. De artikelen uit de (online)tijdschriften van Uitgeverij Boom zijn auteursrechtelijk beschermd. U kunt er natuurlijk uit citeren (voorzien van een bronvermelding) maar voor reproductie in welke vorm dan ook moet toestemming aan de uitgever worden gevraagd.

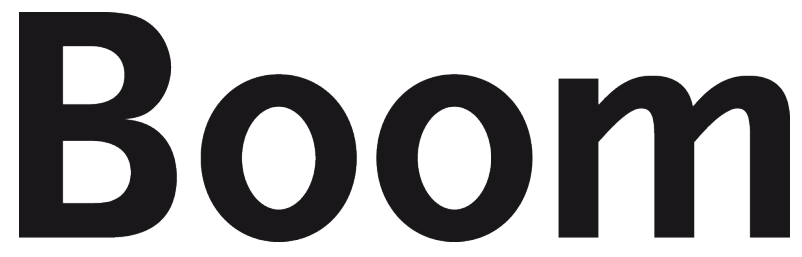

Behoudens de in of krachtens de Auteurswet van 1912 gestelde uitzonderingen mag niets uit deze uitgave worden verveelvoudigd, opgeslagen in een geautomatiseerd gegevensbestand, of openbaar gemaakt, in enige vorm of op enige wijze, hetzij elektronisch, mechanisch door fotokopieën, opnamen of enig andere manier, zonder voorafgaande schriftelijke toestemming van de uitgever.

Voor zover het maken van kopieën uit deze uitgave is toegestaan op grond van artikelen $16 \mathrm{~h} \mathrm{t} / \mathrm{m} \mathrm{16m}$ Auteurswet 1912 jo. Besluit van 27 november 2002, Stb 575, dient men de daarvoor wettelijk verschuldigde vergoeding te voldoen aan de Stichting Reprorecht te Hoofddorp (postbus 3060, 2130 KB, www.reprorecht.nl) of contact op te nemen met de uitgever voor het treffen van een rechtstreekse regeling in de zin van art. 16l, vijfde lid, Auteurswet 1912.

Voor het overnemen van gedeelte(n) uit deze uitgave in bloemlezingen, readers en andere compilatiewerken (artikel 16, Auteurswet 1912) kan men zich wenden tot de Stichting PRO (Stichting Publicatie- en Reproductierechten, postbus 3060, 2130 KB Hoofddorp, www.cedar.nl/pro).

No part of this book may be reproduced in any way whatsoever without the written permission of the publisher.

info@boomamsterdam.nl www.boomuitgeversamsterdam.nl 


\section{Kenmerken en valkuilen van effectief beleid voor genderdiversiteit in de wetenschap}

Romy van der Lee \& Naomi Ellemers*

Genderdiversiteit is een speerpunt geworden in beleid gericht op inclusie en gelijke kansen, ook in de academische wereld. Genderdiversiteit van wetenschappers kan dan ook bijdragen aan kennisontwikkeling en -benutting. Toch is het voor vrouwen nog steeds moeilijker dan voor mannen om succesvol te zijn in de wetenschap. Zelfs als er geen prestatieverschillen waarneembaar zijn, is er een leiderschaps-, loon- en financieringskloof. Dit wordt vaak toegeschreven aan impliciete gender bias: de neiging om academische prestaties van vrouwen minder op te merken of minder te waarderen. Dit gebeurt meestal onbewust, en op elk niveau zijn de verschillen in kansen voor mannen en vrouwen vaak relatief klein. Vrouwen kunnen hierdoor in een vicieuze cirkel terechtkomen: zij ervaren motivatie- en prestatieverlies vanwege achterblijvende kansen en gebrekkig rendement van hun toewijding en behaalde successen. Dit maakt het lastig om het optreden van impliciete discriminatie en de gevolgen ervan te herkennen. Diversiteitsinterventies hebben dan ook vaak niet het gewenste effect, onder andere vanwege onvoldoende draagvlak. We bespreken enkele valkuilen die de effectiviteit van diversiteitsinterventies kunnen belemmeren. Daarnaast geven we suggesties om de effectiviteit van interventies te optimaliseren. Met een evidence-based en context-afhankelijk genderdiversiteitsbeleid is het mogelijk om een gender-diverse academie te bevorderen.

\section{Genderdiversiteit in de wetenschap}

Diversiteit is een actueel onderwerp. Het belang van diversiteit blijkt uit de groeiende wetenschappelijke literatuur over de voor- en nadelen van diversiteit (o.a. Galinsky et al., 2015). Ook binnen de academische wereld krijgt diversiteit, oftewel inclusie van wetenschappers met verschillende gender, etnische en culturele achtergronden steeds meer aandacht. Met name genderdiversiteit en de positie van vrouwelijke wetenschappers is een criterium geworden waar onderzoeksteams expliciet rekening mee dienen te houden (o.a. European Commission, 2013). Er is dan ook een grote hoeveelheid aan empirisch bewijs dat aantoont dat genderdiversiteit goed kan zijn voor wetenschappelijke ontwikkeling, kennisvergaring en benutting (o.a. Nielsen et al., 2017), mits er sprake is van effectieve samenwerking

* Romy van der Lee is verbonden aan de afdeling Organisatiewetenschappen van de Vrije Universiteit Amsterdam. Correspondentieadres: Vrije Universiteit Amsterdam, Faculteit der Sociale Wetenschappen, afdeling Organisatiewetenschappen, De Boelelaan 1105, $1081 \mathrm{HV}$ Amsterdam, tel. 020-5983171, e-mail: r.vander.lee@vu.nl. Naomi Ellemers is verbonden aan de Faculteit der Sociale Wetenschappen van de Universiteit Utrecht. 
(o.a. Van Dijk, Van Engen \& Van Knippenberg, 2012). Met andere woorden, genderdiversiteit in de wetenschap kan lonen.

De feitelijke situatie van de huidige academische wereld toont echter een ander beeld: er is sprake van een leiderschapskloof, salariskloof en financieringskloof tussen mannelijke en vrouwelijke wetenschappers. Vrouwen zijn minder succesvol in alle facetten van de wetenschap dan mannen (Shen, 2013). In Nederland is slechts $19 \%$ van de hoogleraren vrouw; ondanks de relatief hoge percentages vrouwelijke afstudeerders (54\%) en vrouwelijke promovendi (43\%) neemt het aantal vrouwen in elke volgende functiecategorie af (LNVH, 2017). Ook verdienen vrouwelijke wetenschappers gemiddeld 53 euro bruto per maand minder dan hun mannelijke collega's; dit verschil is onverklaarbaar na correctie voor leeftijd, functiecategorie en -niveau (De Goede, Van Veelen \& Derks, 2016). Tevens hebben vrouwen over de hele linie genomen ongeveer $4 \%$ minder kans op het verwerven van een persoonsgebonden Veni-beurs dan mannen (Van der Lee \& Ellemers, 2015a). Deze - relatief kleine - verschillen stapelen zich op, waardoor de academie in een 'diversiteitsarme valkuil' terecht kan komen (O'Brien, Scheffer, Van Nes \& Van der Lee, 2015; Valian, 1998). Dit bemoeilijkt het bewerkstelligen van genderdiversiteit (Ellemers \& Derks, 2017).

De huidige bijdrage heeft dan ook als doel het bieden van een overzicht van de bestaande literatuur omtrent genderdiversiteitsinterventies. We bespreken de kenmerken van effectief beleid alsmede de typische valkuilen op de weg naar gendergelijkheid. We baseren ons hierbij specifiek op de wetenschappelijke context, daar dit een unieke context betreft. Dat wil zeggen, wetenschappers zijn bij uitstek opgeleid om objectief te oordelen en zich te laten informeren door empirisch bewijs. Deze waargenomen objectiviteit zorgt er paradoxaal genoeg voor dat oordelen juist minder objectief kunnen worden (Uhlmann \& Cohen, 2007) en maakt het erkennen van subjectiviteit in oordelen controversieel (Van der Lee \& Ellemers, in press). Hoewel we ook literatuur bespreken uit de bredere organisatiewetenschappen, passen we dit zoveel mogelijk toe op de context van gendergelijkheid in de wetenschap.

\subsection{Impliciete gender bias in de wetenschap}

De verschillende kansen en ongelijke uitkomsten worden vaak toegeschreven aan gebrekkige motivatie, prestatie of ambitie van vrouwen. Wetenschap wordt sterker geassocieerd met mannen dan met vrouwen, en er wordt gedacht dat vrouwen niet het aangeboren talent bezitten dat nodig is voor een succesvolle carrière in de wetenschap (Leslie, Cimpian, Meyer \& Freeland, 2015; Miller, Eagly \& Linn, 2015). Hoewel er feitelijk geen noemenswaardige verschillen blijken te zijn in de prestaties en ambities van mannen en vrouwen (Hyde, 2014), zijn genderstereotypen en traditionele genderrollen hardnekkig en worden ze gebruikt in situaties waarin ze niet van toepassing zijn (Ellemers, 2018). Dit resulteert in ongelijke verwachtingen en beoordelingen van gedrag - ook door beoordelaars die streven naar gelijke beoordelingen. Impliciete gender bias speelt mee, al is het veelal onbewust en onbedoeld, en niet altijd goed te herkennen. Dit zorgt ervoor dat impliciete bias, meer dan expliciete bias, de huidige ongelijkheid in stand kan houden (Barreto \& Ellemers, 2005). 
Expliciete bias (d.w.z. vrouwen zijn ongeschikt om dezelfde prestaties te leveren als mannen) kan eenduidig worden toegeschreven aan (openlijke) discriminatiepraktijken en heeft vaak collectieve protestacties tot gevolg (bijv. de publieke afgang van professor Tim Hunt, Nobel-laureaat, na zijn uitspraken dat 'vrouwelijke wetenschappers voor problemen zorgen in laboratoria ...'; Ratcliff, 2015). Deze vorm van expliciete bias is tevens strafbaar. Impliciete bias is daarentegen minder eenduidig. Het houdt in dat vrouwen net iets minder positief beoordeeld worden, of net iets minder vaak het voordeel van de twijfel krijgen dan mannen wanneer het aankomt op het vervullen van belangrijke functies en het verdelen van belangrijke verantwoordelijkheden. Impliciete bias kan verschillende verschijningsvormen aannemen (Williams \& Dempsey, 2014). Bijvoorbeeld, vrouwen moeten vaak meer bewijs van hun kunnen leveren om als even talentvol en competent te worden gezien en aanspraak te maken op dezelfde (financiering)middelen en promotiemogelijkheden als mannen (o.a. Moss-Racusin, Dovidio, Brescoll, Graham \& Handelsman, 2012; Sheltzer \& Smith, 2014). De verschillende verschijningsvormen maken het moeilijk om het optreden van impliciete bias eenduidig te herkennen; dit geldt zowel voor 'slachtoffers' als voor 'daders', en zowel voor mannen als voor vrouwen. Ook vrouwen kunnen er impliciete bias en negatieve stereotypen ten opzichte van andere vrouwen op na houden: zij leven immers in dezelfde werkelijkheid, waarin zij weinig vrouwen om zich heen zien die succes hebben in de academie.

Tegelijkertijd zeggen veel universiteiten en wetenschappelijke instanties meer genderdiversiteit na te streven, of hebben zelfs beleid dat als doel heeft academische loopbanen van vrouwen te bevorderen. Als vrouwen minder kansen krijgen of minder succesvol blijken, is daarom voor alle partijen de verleiding groot om dit toe te schrijven aan iets wat vrouwen 'niet goed' doen. Dit kan ervoor zorgen dat vrouwen in een vicieuze cirkel terechtkomen: zij ervaren motivatie- en prestatieverlies vanwege achterblijvende kansen en gebrekkig rendement van hun toewijding en behaalde successen (Derks, Van Laar \& Ellemers, 2007; Ryan, Haslam, Hersby, Kulich \& Atkins, 2007). Kleine ongelijkheden kunnen zich gedurende de loopbaan op deze manier opstapelen en resulteren in een meer substantiële ongelijkheid tussen mannen en vrouwen in de wetenschap (zie ook Valian, 1998). In deze bijdrage richten we ons dan ook met name op de kenmerken en valkuilen van interventies die het tegengaan en overkomen van impliciete gender bias als doel hebben. Wij onderscheiden ons hiermee van literatuur die met name gericht is op het vergroten van de representatie van vrouwen (o.a. streefcijfers; Dobbin \& Kalev, 2013). Dat wil zeggen, wij richten ons op interventies die de mechanismen die ervoor zorgen dat vrouwen en mannen ongelijk behandeld worden (inclusief de oorzaken en gevolgen daarvan, en in hoeverre mensen bereid en in staat zijn om dit te onderkennen) aanpakken.

\section{Effectief diversiteitsbeleid}

De aandacht voor genderdiversiteit heeft ook de noodzaak van effectieve interventies vergroot. In de afgelopen jaren zijn dan ook meerdere oproepen gedaan 
door verschillende academici waarin zij pleiten voor de ontwikkeling en implementatie van effectieve diversiteitsinterventies (o.a. Bezrukova, Jehn \& Spell, 2012; Kalinoski, Steele-Johnson, Peyton, Leas, Steinke \& Bowling, 2013; MossRacusin et al., 2014; Paluck, 2006). Over het algemeen genomen dienen effectieve diversiteitsinterventies twee doelen: het creëren van bewustzijn van impliciete associaties en stereotiepe verwachtingen, en het bieden van handvatten die het mogelijk maken om te corrigeren voor deze biases (Bezrukova, Spell, Perry \& Jehn, 2016; Carnes et al., 2012). Het is van essentieel belang dat beide doelen toegelicht worden in interventies. Interventies die zich uitsluitend richten op het creëren van bewustzijn (bijv. door alle deelnemers een Impliciete Associatie Test af te nemen om te laten zien dat zij 'last hebben' van impliciete gender bias), kunnen zorgen voor een gevoel van moedeloosheid en machteloosheid. Al te gemakkelijk ontstaat zo het beeld dat er niets aan te doen is: onbewuste biases zijn er nu eenmaal en daar heeft iedereen last van. De combinatie met het aanleren van methoden om voor deze onbewuste processen te corrigeren blijkt dan ook een cruciaal onderdeel van een effectieve interventie om impliciete bias en ongelijke kansen tegen te gaan. Daarnaast is het van belang dat diversiteitsbeleid en -interventies verankerd zijn in de doelstellingen van de sleutelfiguren en verantwoordelijke personen binnen de organisatie (Dobbin \& Kalev, 2013; Salas \& Cannon-Bowers, 2001). Op deze manier kan er gericht worden aangestuurd op diversiteit, kunnen de specifieke doelstellingen van het beleid gemonitord worden en kunnen - bij onvoldoende resultaat - de verantwoordelijken aangesproken worden. Dit heeft een positief effect op het succes van de diversiteitsinterventie(s).

Hoewel er vele verschillende vormen van beleid en interventies denkbaar zijn (o.a. positieve actie, streefcijfers), wordt in de bestaande literatuur veelal gesproken over de implementatie en effectiviteit van specifiek diversiteitstrainingen. In de bespreking van de kenmerken en valkuilen van diversiteitsbeleid zullen wij ons dan ook voornamelijk richten op de effectiviteit van trainingen ter bevordering van gendergelijkheid in de wetenschap. Wij gaan hierbij verder dan de literatuur die zich richt op maatregelen ter bevordering van de representatie van vrouwen in organisaties, zoals het bijstellen van de organisatiestrategie en het instellen van streefcijfers (o.a. Kalev, Dobbin \& Kelly, 2013). Met andere woorden, wij richten ons met name op de kenmerken en valkuilen van diversiteitstrainingen die beogen impliciete vormen van gender bias tegen te gaan, daar dit ervoor zorgt dat vrouwen anders behandeld en beoordeeld worden waardoor ze minder vaak doorstromen naar hogere functies en vaker de universiteit verlaten (zie ook Ellemers, 2014).

\subsection{De kenmerken van effectief diversiteitsbeleid}

Op basis van de huidige literatuur zijn er meerdere kenmerken te identificeren waaraan effectieve interventies dienen te voldoen ('wise interventions'; Walton, 2014; maar ook: Bezrukova et al., 2012; Dobbin \& Kalev, 2016; Kalev, Dobbin \& Kelly, 2006). Wij noemen hier de belangrijkste punten, en illustreren deze waar mogelijk aan de hand van voorbeelden die betrekking hebben op genderdiversiteit in de wetenschap. 


\section{- Het doel}

Voorafgaand aan de implementatie van een interventie of diversiteitsbeleidsmaatregel dient te worden vastgesteld welk doel de interventie beoogt. Zo kan er, onder andere, onderscheid worden gemaakt tussen korte termijn (bijv. het invullen van een vacature voor hoogleraar met een vrouw) en lange termijn (bijv. gelijke beloning, gelijke kansen op bevordering) doelen, en verschillende leerdoelen, waaronder cognitieve (bijv. vergroten bias geletterdheid) en affectieve (bijv. attitudes ten opzichte van diversiteit; Bezrukova et al., 2012; Tannenbaum \& Yukl, 1992). Helderheid omtrent het specifieke doel van de interventie maakt het tevens mogelijk om de effectiviteit ervan te toetsen. De effectiviteit van een interventie kan worden bepaald door de mate waarin de opgedane kennis en vaardigheden in de praktijk kunnen worden toegepast (d.w.z. transferability; Salas \& Cannon-Bowers, 2001).

Een voorbeeld van een succesvolle interventie met een vooraf bepaalde effectiviteitsmeting betreft de 'gender bias habit-breaking'-interventie (Devine, Forscher, Cox, Kaatz, Sheridan \& Carnes, 2017). In deze training lag de focus op het doorbreken van automatische stereotypische verwachtingspatronen in selectieprocedures. De effectiviteit van deze interventie werd - onder andere - bepaald aan de hand van het percentage vrouwelijke wetenschappers dat werd aangenomen in het jaar na de interventie-implementatie. Uit de resultaten bleek dat wetenschappelijke afdelingen die hadden deelgenomen aan de interventie $18 \%$ meer vrouwen hadden aangenomen ten opzichte van afdelingen die niet deelnamen aan de interventie. Naast het effect op diversiteitsattitudes kon het effect van deze interventie dus in de praktijk toegepast en getoetst worden. Een algemeen geformuleerde en ingezette interventie gericht op 'gelijke kansen' biedt echter geen duidelijk doel, noch de mogelijkheid voor een concrete effectiviteitsmeting waardoor er ruimte ontstaat voor vrije interpretatie van zowel de invulling van de interventie als de toetsing van de effectiviteit. Dit maakt monitoring lastig, maakt het voor deelnemers minder zichtbaar of hun inspanningen zinvol zijn, en verlaagt de kansen op succes.

\section{- De inhoud}

Effectieve diversiteitsinterventies worden gekenmerkt door een aantal inhoudelijke componenten. Ten eerste, interventies dienen evidence-based te zijn, dat wil zeggen effectieve interventies vinden veelal hun grondslag in literatuur en empirisch bewijs voor het optreden van specifieke effecten (Moss-Racusin et al., 2014). Dergelijk bewijs kan worden aangevoerd op twee niveaus:

1 Bij de ontwikkeling van interventies dient rekening te worden gehouden met relevante (psychologische) theorie en eerder onderzoek dat van belang kan zijn. Interventies die gegrond zijn in theorie blijken effectiever te zijn dan interventies die gebaseerd zijn op intuïtie (Moss-Racusin et al., 2016; Walton, 2014). Daarbij komt dat een uitgebreide literatuurstudie voorafgaande aan de ontwikkeling van een interventie kan leiden tot verbetering van reeds bestaande interventies. In plaats van het wiel steeds opnieuw uitvinden is het optimaliseren van bestaande interventies een efficiëntere besteding van mid- 
delen zoals tijd, geld en bereidwilligheid van deelnemers. Dit kan tevens een positieve weerslag op het draagvlak voor de interventie hebben.

2 Bewijs dient aan te tonen wat het 'probleem' in de huidige situatie is en wat de effectiviteit van de genomen maatregelen is. Zo blijkt bijvoorbeeld dat een evidence-based individuele confrontatie met bias de bezorgdheid om de gevolgen van gender bias kan vergroten. Dat wil zeggen, wanneer individuen geconfronteerd worden met bewijs van hun eigen gender bias in een selectieprocedure, vergroot dit hun motivatie en intentie om gender bias in de toekomst tegen te gaan (Parker, Monteith, Moss-Racusin \& Van Camp, 2018). Zonder dergelijk bewijs zijn individuen veel minder bereid theoretische en empirische voorbeelden van gender bias serieus te nemen (ook in vergelijking met raciale bias; Czopp \& Monteith, 2003; Gulker, Mark \& Monteith, 2013). Niet alleen in de ontwikkeling maar ook in de acceptatie heeft een evidence-based benadering dus positieve effecten op de implementatie van diversiteitsinterventies.

Ten tweede, voor het beoogde succes van de interventie is het van belang dat deze verder gaat dan het enkel creëren van bewustzijn van impliciete gender bias (Bezrukova et al., 2016). Bewustwording van, en kennis over de manieren waarop bias diversiteit kan tegenwerken (d.w.z. bias literacy; cognitief leerdoel), is echter wel een eerste stap. Zonder herkenning wordt het immers lastig om ervoor te corrigeren. Vervolgens dient een effectieve interventie handvatten te bieden die deelnemers in staat stellen om te corrigeren voor impliciete bias, wanneer deze herkend wordt. Enkele voorbeelden van dergelijke strategieën zijn individualiseren in plaats van generaliseren (bijv. focussen op concrete informatie over specifieke kwalificaties), het perspectief aannemen van een vrouwelijke kandidaat of vrouwelijk commissielid, en oordelen op basis van gevoel of intuïtie te vermijden maar standpunten of voorkeuren te verankeren in concrete evidentie (Carnes et al., 2012). Counter-stereotypering (bijv. het associëren van 'vrouwen' met 'leider') is een andere methode, hoewel deze strategie alleen positieve effecten lijkt te hebben op het reduceren van gender bias tijdens selectieprocedures mits er enige tijd tussen de interventie en de procedure zit of wanneer er sprake is van langdurige blootstelling aan het counterstereotype (Dasgupta \& Asgari, 2004; Kawakami, Dovidio \& Van Kamp, 2005; zie ook Burns, Monteith \& Parker, 2017). Al met al is gebleken dat de combinatie van meerdere interventies gericht op zowel het creëren van bewustwording van impliciete bias als het aanbieden van strategieën om hiermee om te gaan een bewezen langdurige vermindering van impliciete bias tot gevolg kan hebben, en mensen meer alert kan maken voor het optreden van mogelijke bias (Carnes et al., 2015; Devine, Forscher, Austin \& Cox, 2012). Effectieve diversiteitsinterventies vergroten dus zowel de bias geletterdheid als de zelfdoeltreffendheid van deelnemers.

Ten derde, er dient rekening gehouden te worden met de duur van de interventie. Deelnemers aan diversiteitsinterventies in de academie zijn veelal hoogleraren en universitair (hoofd)docenten die - op vrijwillige basis - zitting hebben in een aanstellings-, beoordelings- of bevorderingscommissie. Het verzoek om deel te nemen aan een uitgebreide (bijv. meerdaagse) diversiteitsinterventie zal in de praktijk dan ook op weerstand stuiten; commissieleden zijn wellicht bereid om 
deel te nemen aan een dergelijke tijdsintensieve interventie, maar zijn vanwege andere verplichtingen hier niet toe in staat. Om de vrijwillige participatie te verhogen dient een effectieve interventie dan ook zo kort en bondig mogelijk gemaakt te worden. Daarnaast is het van belang dat een interventie een actieve, of bij voorkeur zelfs een interactieve leermodule bevat (Moss-Racusin et al., 2014). Dat wil zeggen, het enkel passief lezen van een tekst waarin de manieren staan beschreven waarop impliciete gender bias beoordelingen kan beïnvloeden, is onvoldoende om een verandering teweeg te brengen. Toch is dit vaak de vorm waarin interventies worden aangeboden. Dit is bijvoorbeeld het geval voor een online interventiemodule die onderdeel uitmaakt van het brede diversiteitsprogramma Athena SWAN Charter in het Verenigd Koninkrijk (www.ecu.ac.uk/equality-charters/athena-swan/): deze betreft alleen het passief lezen van informatie. De effectiviteit van deze module voor het veranderen van het bewustzijn, de intenties of de gedragingen van individuele beoordelaars kon niet eenduidig worden vastgesteld (Sweetman \& Barreto, 2016). Voor het bewerkstelligen van langdurige attitudeverandering en actiebereidheid ten opzichte van diversiteit is het van belang dat een interventie ten minste deels bestaat uit een (inter)actieve module. Succesvolle voorbeelden van dergelijke actieve leercomponenten zijn discussies over de eigen ervaringen - als beoordelaar of als kandidaat - met impliciete gender bias, rollenspellen, of het bespreken van casuïstiek (Carnes et al., 2012). Effectieve diversiteitsinterventies zijn dus veelal kort en (inter)actief van aard.

\section{- De deelnemers}

Naast het formuleren van het concrete doel van de interventie en de verschillende inhoudelijke componenten is het ook belangrijk dat de interventie zo specifiek mogelijk wordt toegespitst op de behoeften en kenmerken van de deelnemers aan de interventie om zodoende de relevantie te optimaliseren (o.a. Tannenbaum \& Yukl, 1992; Walton, 2014). In het geval van een diversiteitstraining gericht op het elimineren van impliciete gender bias tijdens selectieprocedures, bijvoorbeeld, zullen beoordelaars uit de exacte wetenschappen minder overtuigd zijn van de noodzaak van een training wanneer de gepresenteerde evidentie van gender bias gericht is op voorbeelden uit de sociale wetenschappen - en andersom. Daarnaast is uit onderzoek gebleken dat een diversiteitstraining met name positieve effecten heeft op teams die vooraf minder positief zijn over diversiteit, en teams waarin de diversiteit zichtbaar is (d.w.z. direct relevant; Homan, Buengeler, Eckhoff, Van Ginkel \& Voelpel, 2015; zie ook: Apfelbaum, Stephens \& Reagans, 2016; Roberson, Kulik \& Pepper, 2001). Een context-afhankelijke diversiteitsinterventie waarbij wordt ingespeeld op de achtergrond van de deelnemers en specifieke kenmerken van de situatie die men wil veranderen heeft de meeste kans van slagen.

Daarnaast dient er ook rekening te worden gehouden met het psychologische proces dat achter het doel van de interventie zit. Ter illustratie, in het geval van het benoemen van een vrouwelijke hoogleraar blijkt een interventie in de vorm van het vergroten van het aantal vrouwen in de beoordelingscommissie een effectieve beleidsaanpassing (Van den Brink, 2011). Dezelfde maatregel blijkt echter niet effectief in het bewerkstelligen van evenredige honoreringspercentages voor mannelijke en vrouwelijke aanvragers van een NWO Veni-beurs (Van der Lee \& 
Ellemers, 2015a). Dit kan worden verklaard door de verschillende psychologische processen die ten grondslag liggen aan deze verschillende vormen van beoordelen. Zo gaat het bij het bevorderen van een vrouw tot hoogleraar om geëlaboreerde informatieverwerking van het curriculum vitae en de behaalde prestaties van één tot enkele individuen, terwijl het bij het selecteren van (vrouwelijke) kandidaten voor beurzen aannemelijk is dat er sprake is van oppervlakkige verwerking van de curricula vitae en de potentie van een groot aantal individuen in een relatief kort tijdsbestek. Terwijl geëlaboreerde informatieverwerking impliciete gender bias tegen kan gaan, kan heuristische informatieverwerking impliciete gender bias en stereotypering juist in de hand werken (Devine, 1989), vanwege de hoge cognitieve lading en de tijdsdruk die op commissieleden wordt gelegd. Daar de kennis van (gender)stereotypen cultureel bepaald is en niet gender-afhankelijk (d.w.z. iedereen heeft dezelfde kennis van genderstereotypen), leidt een beleidsmaatregel als meer vrouwen in de selectiecommissie in het geval van beurstoekenningen niet tot meer evenredige honoreringen van mannen en vrouwen (Van der Lee \& Ellemers, 2015a).

Een ander voorbeeld betreft de gelijktijdige en gezamenlijke beoordeling van kandidaten. In vergelijking met een individuele beoordelingsprocedure waarin kandidaten afzonderlijk worden beoordeeld, heeft een gelijktijdige beoordelingsprocedure waarin twee kandidaten direct met elkaar worden vergeleken, een positief effect op de selectie van de meest geschikte kandidaat, en daarmee op de kansen van de vrouwelijke kandidaat (Bohnet, Van Geen \& Bazerman, 2016). Een meer omvangrijke gezamenlijke beoordelingsprocedure, zoals bij de selectie van beursaanvragen, heeft echter geen positief effect op de kansen van vrouwelijke kandidaten (Van der Lee \& Ellemers, 2015a). Effectieve interventies houden dus niet alleen rekening met de achtergrond van de deelnemers aan de interventie maar ook met de aard van de (beoordelings)situatie, en de rol en taak die de deelnemers vervullen met betrekking tot genderdiversiteit.

Een derde punt betreffende de deelnemers is de manier waarop zij benaderd worden. Het toevoegen van een diversiteitsinterventie aan een reeds bestaande beoordelingsprocedure kan vragen oproepen over de kwaliteit van de voorafgaande procedure. Dit wekt gemakkelijk de indruk dat het huidige gebrek aan diversiteit althans ten dele wordt toegeschreven aan de manier waarop eerdere procedures zijn ingevuld. Zeker wanneer beoordelaars herhaaldelijk zitting nemen in de beoordelingsprocedure, kan dit een schuldgevoel oproepen voor het gebrek aan diversiteit of het falen van het reeds bestaande diversiteitsbeleid. Dergelijke opgelegde schuldgevoelens voor de huidige problemen hinderen de effectiviteit van de interventie (Moss-Racusin et al., 2014). Sterker nog, wanneer de maatschappelijke roep om het onderdrukken van bias wordt benadrukt, kan dit weerstand oproepen bij deelnemers waardoor zij zelfs meer expliciete en impliciete bias vertonen (Legault, Gutsell \& Inzlicht, 2011). Hoewel er soms gepleit wordt voor het verplicht stellen van diversiteitstraining voor beoordelaars (Bell, Connerley \& Cocchiara, 2009), kan deze vorm van druk er dus ook voor zorgen dat de mate van bias juist versterkt wordt. Het is dus belangrijk om heel zorgvuldig te communiceren over de wens om diversiteitsdoelen te behalen. Hierbij kan het helpen om meer naar de toekomst te kijken dan naar het verleden, en vooral te communice- 
ren over de wens een ideaal van gelijke kansen te bereiken, in plaats van mensen te verplichten om waardevolle uitkomsten gelijk te verdelen (Does, Derks \& Ellemers, 2011).

\subsection{De valkuilen van beleidsinitiatieven}

Om het succes van diversiteitsinterventies te vergroten dient bij de ontwikkeling en implementatie rekening te worden gehouden met de hiervoor beschreven randvoorwaarden. Toch gaat het met enige regelmaat mis. Goedbedoelde interventies, waarin veelvuldig middelen zoals tijd en geld zijn geïnvesteerd, blijken niet het beoogde effect te hebben. Er verandert niets, en men wordt moedeloos van mislukte en kostbare pogingen. Soms blijken 'gezond verstand' oplossingen zelfs contraproductief te werken (Major \& Kaiser, in press; zie ook Kalev, Dobbin \& Kelly, 2006). Bijvoorbeeld, het intuïtieve idee dat de aanwezigheid van vrouwen in een selectiecommissie ervoor zal zorgen dat vrouwelijke kandidaten niet achtergesteld worden. Uit onderzoek blijkt echter dat dit niet vanzelfsprekend het geval is; succesvolle vrouwen zijn soms zelfs minder bereidwillig dan mannen om hun jongere vrouwelijke collega's te ondersteunen en te helpen (Derks, Van Laar \& Ellemers, 2016; Duguid, 2011). Er zijn dan ook enkele algemene valkuilen te identificeren waar beleidsmakers of andere verantwoordelijken voor dienen te waken tijdens de ontwikkeling en implementatie van diversiteitsinterventies.

\section{- Weerstand tegen empirisch bewijs van genderongelijkheid}

Een eerste valkuil in de implementatie van diversiteitsinterventies betreft de acceptatie van bewijs van ongelijke kansen. Alvorens diversiteitsinterventies breed gedragen worden, dient er enige consensus te bestaan over de mate waarin er inderdaad sprake is van een probleem. Met andere woorden, er dient eerst overeenstemming te zijn over de mate waarin er sprake is van ongelijke kansen en in hoeverre het nodig is om daar actief beleid tegen te voeren. Er zijn twee ontwikkelingen die de acceptatie van evidentie voor ongelijke kansen kunnen belemmeren (Van der Lee \& Ellemers, in press):

1 In de literatuur zijn onderzoeken met tegenstrijdige resultaten te vinden. Dat wil zeggen, naast de veelheid aan studies die ongelijke kansen voor mannen en vrouwen in de wetenschap rapporteren, zijn er ook studies die gelijke kansen voor mannen en vrouwen rapporteren of zelfs studies die een voorkeursbehandeling van vrouwen laten zien (Ceci, Ginther, Kahn \& Williams, 2014; Williams \& Ceci, 2015). Deze ogenschijnlijke tegenstrijdigheden kunnen er gemakkelijk toe leiden dat mensen denken dat er feitelijk geen probleem is, of dat het eerst maar eens duidelijk moet worden of vrouwen inderdaad minder kansen hebben op een succesvolle loopbaan in de academie. Wie deze studies meer in detail bekijkt, ziet echter al snel dat uiteenlopende observaties en resultaten simpelweg verklaard kunnen worden doordat ze een geheel andere vraagstelling, invalshoek, methodologie of uitkomst centraal stellen. Bijvoorbeeld, onder bepaalde omstandigheden, zoals een afgebakende experimentele beoordelingssituatie waarin een vrouwelijke kandidaat die overduidelijk zeer gekwalificeerd is expliciet wordt voorgedragen door de voorzitter van de selectiecommissie, nemen de kansen voor de vrouwelijke kandidaat toe (Leslie, 
Manchester \& Dahm, 2017; Williams \& Ceci, 2015; zie ook Biernat \& Fuegen, 2001). De situatie die hier is onderzocht, kenmerkt zich echter door een aantal belangrijke voorwaarden, waardoor impliciete gender bias weinig kans krijgt om het beoordelingsproces te beïnvloeden. Dit is niet goed vergelijkbaar met de meer natuurlijke situaties waarin deelnemers zelf wordt gevraagd om een keuze te maken uit verschillende dossiers, en naar eigen inzicht een oordeel te vormen over een vrouwelijke kandidaat die zij niet kennen en waar de kwalificaties wellicht minder eenduidig zijn, zoals onderzocht in andere studies (o.a. Moss-Racusin et al., 2012; zie ook Dovidio \& Gaertner, 200o). Wanneer er ambiguiteit heerst over de criteria of de kwalificaties van kandidaten, is er een veel groter risico dat impliciete bias een negatief effect heeft op de kansen van vrouwelijke kandidaten.

2 Onderzoeken die empirische evidentie voor ongelijke kansen voor mannen en vrouwen in de wetenschap laten zien, worden vaak sceptisch ontvangen en in populaire media bekritiseerd op basis van wetenschappelijk niet-valide argumenten, die voor leken moeilijk controleerbaar zijn (o.a. Leslie et al., 2015; MossRacusin et al., 2012; Van der Lee \& Ellemers, 2015a). Dit gebeurt niet alleen door representanten van het algemene publiek, die het ongeloofwaardig vinden dat wetenschappers niet in staat zouden zijn om objectief te oordelen (o.a. MossRacusin, Molenda \& Cramer, 2015), maar ook door wetenschappelijke collega's, die met oneigenlijke argumenten de geloofwaardigheid van onderzoekers en de door hen gebruikte onderzoeksmethoden proberen onderuit te halen (o.a. Handley, Brown, Moss-Racusin \& Smith, 2015). Er wordt bijvoorbeeld aangegeven dat een bepaalde onderzoeksmethode of statistische analyse 'fout' is, terwijl er tegenstrijdige adviezen worden gegeven over wat dan de 'goede' methode zou zijn. Of er wordt voorbijgegaan aan de observatie dat een andere berekening niets verandert aan de centrale bevindingen of de conclusies die daaruit volgen (Van der Lee \& Ellemers, 2015b; 2015c). Dit kan ervoor zorgen dat mensen die de discussie niet goed gevolgd hebben, vraagtekens zetten bij het onderzoek dat is gedaan. Als gevolg hiervan denkt men algauw dat resultaten niet eenduidig zijn, of neemt men aan dat het wel meevalt met de mate waarin er sprake is van ongelijke kansen. Zelfs als de kritiek ongegrond blijkt, is deze dus schadelijk, omdat het ondermijnend werkt voor de legitimiteit van beleidsaanpassingen die betrekking hebben op het bevorderen van genderdiversiteit (Van der Lee \& Ellemers, in press). Dit kan vervolgens resulteren in het verlies van draagvlak voor de implementatie van diversiteitsinterventies.

Weerstand tegen empirisch bewijs voor bias lijkt tevens specifiek te zijn voor gender bias (Cislak, Formanowicz \& Saguy, 2018). Dat wil zeggen, in vergelijking met een andere vorm van sociale ongelijkheid, zoals raciale bias, ontvangt onderzoek naar gender bias minder financiering en wordt het gepubliceerd in minder invloedrijke tijdschriften. Gezien de ontwikkelingen die de acceptatie van evidentie voor ongelijke kansen kunnen belemmeren, is het dus van belang dat er nauwkeurig gekeken wordt naar de studies die zijn gedaan en de evidentie die er is voor (on)gelijkheid alvorens dit kan worden ingezet om beleidsaanpassingen te rechtvaardigen. 
- Er is geen 'gouden tip'

Wanneer een diversiteitsinterventie effectief is gebleken, is het aanlokkelijk om dezelfde interventie ook elders te implementeren, omdat 'succes gegarandeerd' lijkt. Men is geneigd te denken dat - eindelijk - de oplossing is gevonden voor het probleem, en dat die oplossing dus ook in andere situaties (d.w.z. afdelingen, universiteiten, commissies) tot succes zal leiden. Er is echter geen 'gouden tip' die altijd werkt. Met andere woorden, er speelt een complex van elkaar beïnvloedende oorzaken, en er is dus - helaas - geen eenduidige simpele oplossing aan te geven die altijd werkt om diversiteit en gelijke kansen te bevorderen en impliciete bias tegen te gaan. Zoals hierboven is uiteengezet, speelt de mate waarin de specifieke context (o.a. discipline, beoordelingsprocedure, deelnemers) is meegenomen in de ontwikkeling en implementatie een cruciale rol bij de slagingskans van elke interventie (o.a. Apfelbaum et al., 2016). Wanneer iets wat effectief is gebleken in de ene situatie klakkeloos wordt overgenomen in een andere situatie zonder oog voor de veranderende context, zal dit een negatief effect hebben op de effectiviteit. Op termijn leidt het herhaaldelijk vertellen van dit soort 'succesverhalen' tot ongewenste effecten zoals verminderde welwillendheid van deelnemers om steeds weer iets nieuws te proberen (Legault et al., 2011). Het loont dus de moeite om de bruikbare elementen van een effectieve interventie dusdanig aan te passen dat deze zo goed mogelijk aansluiten op de huidige situatie waarin de interventie geïmplementeerd gaat worden. In eerste instantie lijkt dit misschien een omslachtige werkwijze voor mensen die meteen aan de slag willen, maar uiteindelijk zal een meer zorgvuldige analyse van de situatie en waar deze om vraagt, het snelst tot een zichtbaar resultaat leiden.

\section{- Paradox van gelijkheid}

Een derde valkuil betreft het heersende idee dat het implementeren van diversiteitsbeleid op zichzelf voldoende is om gelijke kansen te bevorderen. Deze aanname is onjuist. De aandacht voor het belang van diversiteit op beleidsniveau doet vermoeden dat het in de betreffende organisatie wel goed zal zitten met de diversiteit. Er is immers op hoog, bestuurlijk niveau aandacht voor diversiteit en gelijke kansen. Maar als het beleid niet met succes wordt doorgevoerd, kan dit beeld ook averechts werken. Het kan er bijvoorbeeld toe leiden dat uitvoerders van het beleid (o.a. beoordelings- en selectiecommissies) minder alert zijn op het optreden van impliciete bias en ongelijke kansen. Deze verminderde alertheid zorgt er vervolgens voor dat stereotypering en impliciete bias juist meer meespelen tijdens beoordelingsprocedures. Diverse onderzoeken hebben in verschillende situaties aangetoond dat dit zo kan werken. Dit verschijnsel wordt ook wel de 'paradox van gelijkheid' genoemd (bijv. Castilla \& Bernard, 2010; Kaiser et al., 2013). Daarnaast is het zo dat personen die in hun werk veel beslissingen nemen, meer geneigd zijn te denken dat ze goed in staat zijn objectief te oordelen. Zij hebben hier immers veel ervaring mee, waardoor ze gemakkelijk denken dat cognitieve en motivationele biases zaken zijn waar anderen vooral last van hebben - niet zijzelf (Pronin, Gilovich \& Ross, 2004). Deze overtuiging van eigen objectiviteit blijkt echter juist het optreden van bias in de hand te kunnen werken, vanwege de verminderde alertheid voor bias die we hiervoor hebben beschreven (Uhlmann \& Cohen, 2007). 
Deze valkuil is met name voor de wetenschap relevant, omdat wetenschappers bij uitstek professionals zijn die zichzelf zien als experts in het nemen van rationele beslissingen gebaseerd op objectief bewijs. Wetenschappers gebruiken allerlei technieken en procedures om objectief en onafhankelijk onderzoek te doen, en trainen zichzelf en elkaar om accurate en onbevooroordeelde beslissingen te nemen. Dit werkt gemakkelijk het beeld in de hand dat wetenschappers goed in staat zijn onafhankelijk en objectief te oordelen - ook wanneer het aankomt op beslissingen over de loopbanen van andere onderzoekers (Kaatz, Gutierrez \& Carnes, 2014). De eigen waargenomen objectiviteit die wetenschappers vaak zelf als sterk punt zien, kan dus juist een belangrijke valkuil zijn die bijdraagt aan het optreden van bias in de wetenschap.

\section{Conclusie: naar een gender-diverse academie}

Evenredige gendervertegenwoordiging is een maatschappelijk - en wetenschappelijk - ijkpunt geworden. Nederland scoort in dit opzicht slecht in vergelijking met omringende landen (European Commission, 2016). De wetenschap lijdt niet alleen onder de ondervertegenwoordiging van vrouwelijk talent, maar ook onder geringe raciale, culturele en seksuele diversiteit (Nature, 2014). Hoewel de mechanismen die bijdragen aan de instandhouding van verschillende vormen van ongelijkheid overlap vertonen (Devine, 1989), is genderongelijkheid een unieke situatie onder andere omdat vrouwen numeriek gezien in de meerderheid zijn (Radke, Hornsey \& Barlow, 2016; zie ook Cislak et al., 2018). De voortdurende constatering van ongelijke kansen en ongelijke uitkomsten voor mannen en vrouwen, zelfs als zij niet van elkaar verschillen wat betreft opleiding, ervaring, of prestaties, krijgt dan ook steeds meer aandacht. Het vergroten van genderdiversiteit lijkt een goed ideaal om na te streven ('moral case'; Crosby, Iyer, Clayton \& Downing; 2003) en kan ook een meerwaarde geven voor iedereen ('business case'; Nielsen et al., 2017). Toch is het voor vrouwen nog steeds moeilijker dan voor mannen om succesvol te zijn in de wetenschap.

Impliciete gender bias is subtiel en treedt vaak onbewust op, en verschillen in de kansen die mannen en vrouwen krijgen, zijn vaak relatief klein. Zo wordt bijvoorbeeld van vrouwen verwacht dat zij aan alle beoordelingscriteria voldoen, terwijl mannen vaker het voordeel van de twijfel krijgen als zij niet excelleren op enkele van de gestelde criteria (Van den Brink \& Benschop, 2012). Daarnaast is de wetenschap bij uitstek een omgeving waarin men waarde hecht aan objectiviteit, zo ook in het beoordelen van collega's. Deze waargenomen objectiviteit kan er echter voor zorgen dat men minder alert is op genderstereotypen waardoor bias juist vaker kan optreden (Uhlmann \& Cohen, 2007). Dit maakt het extra lastig om impliciete gender bias te herkennen en verzwakt de motivatie om diversiteitsinterventies te implementeren (Ellemers \& Barreto, 2009; Radke et al., 2016).

Veel diversiteitsinitiatieven bereiken dan ook niet het gewenste effect. Ondanks goede intenties en investering van middelen zoals tijd en geld blijken de geïmplementeerde interventies vaak niet effectief in het bevorderen van genderdiversiteit. Een van de moeilijkheden bij een succesvolle implementatie van diversiteits- 
beleid betreft de vaak sceptische reacties op onderzoeken die gender bias in de wetenschap aantonen (Handley et al., 2015). Om het draagvlak voor diversiteitsbeleid te vergroten is het dan ook van belang dat interventies de schuldvraag over het huidige gebrek aan diversiteit zoveel mogelijk vermijden; het bewerkstelligen van genderdiversiteit is een gedeelde verantwoordelijkheid van de organisatie en beoordelaars (o.a. Moss-Racusin et al., 2014). Daarnaast heerst er vaak de illusie van een 'gouden tip'. Er is geen eenduidige interventie die in elke context kan worden gebruikt of gegarandeerd tot succes zal leiden (o.a. Apfelbaum et al., 2016). Het overnemen van een interventie die succesvol is gebleken in de ene situatie, zal niet automatisch tot succes leiden in een andere situatie. Tevens is gebleken dat het opstellen van diversiteitsbeleid op zichzelf niet voldoende is om gelijke kansen voor mannen en vrouwen te bewerkstelligen. Paradoxaal genoeg kan het bestaan van - algemeen - diversiteitsbeleid juist ongelijke kansen in de hand werken omdat beoordelaars, door kennis over het bestaan van beleid, minder vigilant zijn op impliciete bias tijdens de uitvoering van het beleid (o.a. Kaiser et al., 2013). Deze valkuilen kunnen ervoor zorgen dat geïmplementeerde interventies niet het gewenste effect bereiken en kunnen leiden tot moedeloosheid.

Er zijn echter ook een aantal kenmerken van diversiteitsinterventies te identificeren die het succes ervan kunnen vergroten. Ten eerste, om de effectiviteit zo eenduidig mogelijk te kunnen vaststellen dient vooraf aan de ontwikkeling en implementatie te worden vastgesteld welk concreet doel de interventie beoogt. Het bewerkstelligen van gelijke beloning of gelijke kansen op bevordering vergen namelijk verschillende typen interventies. De effectiviteit van de interventie kan vervolgens worden bepaald door de mate waarin de opgedane kennis en vaardigheden toepasbaar zijn in de praktijk en leiden tot realisatie van het gestelde doel (Salans \& Cannon-Bowers, 2001). Ten tweede, effectieve diversiteitsinterventies worden ook gekenmerkt door een aantal inhoudelijke componenten. Zo zijn evidence-based interventies over het algemeen effectiever dan interventies gebaseerd op intuïtie (Moss-Racusin et al., 2014). Daarnaast dient een interventie zich niet alleen te richten op het vergroten van het bewustzijn van, en kennis over, het bestaan van gender bias (d.w.z. bias geletterdheid), maar dient deze ook concrete handvatten te bieden om hiervoor te corrigeren (o.a. Carnes et al., 2012). Tevens dient een effectieve interventie een (inter)actieve component te bevatten die deelnemers, bijvoorbeeld, in staat stelt om te leren van de eigen ervaringen met gender bias (o.a. Parker et al., 2018). Ten derde, effectieve diversiteitsinterventies worden zoveel mogelijk toegespitst op de kenmerken en behoeften van de deelnemers. Een succesvolle interventie is context-afhankelijk en spreekt de specifieke psychologische processen aan waarin impliciete gender bias kan optreden (Walton, 2014). Dat wil zeggen, per situatie dient rekening te worden gehouden met de achtergrond van de deelnemers aan de interventie en beoordelingsprocedure waarin de interventie wordt geïmplementeerd.

Hoewel het bewerkstelligen van genderdiversiteit en het implementeren van diversiteitsbeleid niet eenduidig is, kunnen interventies wel degelijk tot succes leiden. Diversiteitsbeleid dient echter wel te worden verankerd in de doelstellingen van de organisatie, sleutelfiguren en verantwoordelijken (Dobbin \& Kalev, 2013), en bewezen effectieve interventies worden aangepast aan de huidige situ- 
atie en beoogde doelen van het diversiteitsbeleid. Waar wij ons met name hebben gericht op de effectiviteit van diversiteitstrainingen, zijn de beschreven kenmerken en valkuilen ook in meer of mindere mate toepasbaar op andere vormen van interventies (o.a. streefcijfers en mentorprogramma's) gericht op gendergelijkheid in de wetenschap. Interventies die de bovengenoemde kenmerken in acht nemen, hebben de meeste kans op succes in het bewerkstelligen van gelijke kansen voor mannen en vrouwen en het bevorderen van een gender-diverse academie.

\section{Praktijkbox}

Wat betekenen de resultaten voor de praktijk?

- Genderdiversiteit in de wetenschap kan bijdragen aan kennisontwikkeling en -benutting.

- Er is echter nog steeds sprake van een leiderschapskloof, salariskloof en financieringskloof. De ongelijke kansen voor mannelijke en vrouwelijke wetenschappers kunnen onder andere worden toegeschreven aan de aanhoudende impliciete gender bias in beoordelingsprocedures. Dit zorgt er bijvoorbeeld voor dat de mate van competentie en ambitie van vrouwen anders wordt beoordeeld dan die van mannen.

- Effectieve diversiteitsinterventies, specifiek diversiteitstrainingen, bevatten een concrete formulering van het beoogde doel. De effectiviteit kan vervolgens worden bepaald door de mate waarin de opgedane kennis en vaardigheden toepasbaar zijn in de praktijk.

- Effectieve diversiteitsinterventies worden gekenmerkt door een aantal inhoudelijke componenten: ze zijn evidence-based, ze vergroten de kennis over impliciete bias en reiken handvatten aan om hiervoor te corrigeren, en ze zijn kort en (inter)actief van aard.

- Er is geen 'gouden tip' om gelijke kansen te bevorderen; effectieve interventies worden op maat gemaakt en toegespitst op de behoeften en kenmerken van de deelnemers aan de interventie.

- Het simpelweg aankondigen van diversiteitsbeleid is op zichzelf niet voldoende en kan ongelijke kansen juist in de hand werken. Interventies dienen te worden verankerd in de doelstellingen van de organisatie en verantwoordelijke sleutelfiguren.

\section{Literatuur}

Apfelbaum, E.P., Stephens, N.M., \& Reagans, R.E. (2016). Beyond one-size-fits-all: Tailoring diversity approaches to the representation of social groups. Journal of Personality and Social Psychology, 111, 547-566.

Bell, M.P., Connerley, M., \& Cocchiara, F. (2009). The case for mandatory diversity education. Academy of Management Learning \& Education, 8, 597-609.

Barreto, M., \& Ellemers, N. (2005). The burden of benevolent sexism: How it contributes to the maintenance of gender inequalities. European Journal of Social Psychology, 35, 633-642. 
Bezrukova, K., Jehn, K.A., \& Spell, C.S. (2012). Reviewing diversity training: Where we have been and where we should go. Academy of Management Learning \& Education, 11, 207-227.

Bezrukova, K., Spell, C.S., Perry, J.L., \& Jehn, K.A. (2016). A meta-analytical integration of over 40 years of research on diversity training evaluation. Psychological Bulletin, 142, 1227-1274.

Biernat, M., \& Fuegen, K. (2001). Shifting standards and the evaluation of competence: Complexity in gender-based judgment and decision making. Journal of Social Issues, 57, 707-724.

Bohnet, I., Van Geen, A., \& Bazerman, M. (2016). When performance trumps gender bias: Joint vs. separate evaluation. Management Science, 62, 1225-1234.

Burns, M.D., Monteith, M.J., \& Parker, L.R. (2017). Training away bias: The differential effects of counterstereotype training and self-regulation on stereotype activation and application. Journal of Experimental Social Psychology, 73, 97-110.

Carnes, M., Devine, P.G., Baier Manwell, L., Byars-Winston, A., Fine, E., Ford, C.E., ... Sheridan, J. (2015). Effect of an intervention to break the gender bias habit for faculty at one institution: A cluster randomized, controlled trial. Academic Medicine, 90, 221230.

Carnes, M., Devine, P.G., Isaac, C., Manwell, L., Ford, C.E., Byars-Winston, A., ... Sheridan, J. (2012). Promoting institutional change through bias literacy. Journal of Diversity in Higher Education, 5, 63-77.

Castilla, E.J., \& Bernard, S. (2010). The paradox of meritocracy in organizations. Administrative Science Quarterly, 55, 543-576.

Ceci, S.J., Ginther, D.K., Kahn, S., \& Williams, W.M. (2014). Women in academic science: A changing landscape. Psychological Science in the Public Interest, 15, 75-141.

Cislak, A., Formanowicz, M., \& Saguy, T. (2018). Bias against research on gender bias. Scientometrics, 115, 189-200.

Crosby, F.J., Iyer, A., Clayton, S., \& Downing, R.A. (2003). Affirmative action: Psychological data and the policy debates. American Psychologist, 58, 93-115.

Czopp, A.M., \& Monteith, M.J. (2003). Confronting prejudice (literally): Reactions to confrontations of racial and gender bias. Personality and Social Psychology Bulletin, 29, 532544.

Dasgupta, N., \& Asgari, S. (2004). Seeing is believing: Exposure to counterstereotypic women leaders and its effect on the malleability of automatic gender stereotyping. Journal of Experimental Social Psychology, 40, 642-658.

De Goede, M., Van Veelen, R., \& Derks, B. (2016). Financiële beloning van mannen en vrouwen in de wetenschap. Onderzoek uitgevoerd in opdracht van het Landelijk Netwerk Vrouwelijke Hoogleraren.

Derks, B., Van Laar, C., \& Ellemers, N. (2007). The beneficial effects of social identity protection on the performance motivation of members of devalued groups. Social Issues and Policy Review, 1, 217-256.

Derks, B., Van Laar, C., \& Ellemers, N. (2016). The Queen Bee Phenomenon: Why women leaders distance themselves from junior women. The Leadership Quarterly, 27, 456-469.

Devine, P.G. (1989). Stereotypes and prejudice: Their automatic and controlled components. Journal of Personality and Social Psychology, 56, 5-18.

Devine, P.G., Forscher, P.S., Austin, A.J., \& Cox, W.T.L. (2012). Long-term reduction in implicit race bias: A prejudice habit-breaking intervention. Journal of Experimental Social Psychology, 48, 1267-1278.

Devine, P.G., Forscher, P.S., Cox, W.T.L., Kaatz, A., Sheridan, J., \& Carnes, M. (2017). A gender bias habit-breaking intervention led to increased hiring of female faculty in STEMM departments. Journal of Experimental Social Psychology, 73, 211-215. 
Dobbin, F., \& Kalev, A. (2013). The origins and effects of corporate diversity programs. In Q.M. Roberson (Ed.), Oxford Handbook of Diversity and Work (pp. 253-281). New York: Oxford University Press.

Dobbin, F., \& Kalev, A. (2016). Why diversity programs fail. Harvard Business Review, 94, 14-22.

Does, S., Derks, B., \& Ellemers, N. (2011). Thou shall not discriminate: How emphasizing moral ideals rather than obligations increases whites' support for social equality. Journal of Experimental Social Psychology, 47, 562-571.

Dovidio, J.F., \& Gaertner, S.L. (2000). Aversive racism and selection decisions: 1989 and 1999. Psychological Science, 11, 315-319.

Duguid, M. (2011). Female tokens in high-prestige work groups: Catalysts or inhibitors of group diversification? Organizational Behavior and Human Decision Processes, 116, 104115 .

Ellemers, N. (2014). Women at work: How organizational features impact career development. Policy Insights from Behavioral and Brain Sciences, 1, 46-54.

Ellemers, N. (2018). Gender stereotypes. Annual Review of Psychology, 69, 275-298.

Ellemers, N., \& Barreto, M. (2009). Collective action in modern times: How modern expressions of prejudice prevent collective action. Journal of Social Issues, 65, 749-768.

Ellemers, N., \& Derks, B. (2017). Eenzaam aan de top: Negatieve bijwerkingen van de ondervertegenwoordiging van vrouwen in hoge functies. In M. Lückerath-Rovers, B. Bier, H. van Ees \& M. Kaptein (Red.), Jaarboek Corporate Governance 2017-2018 (p. 43-56). Deventer: Wolters Kluwer.

European Commission. (2013). Fact sheet: Gender Equality in Horizon2020. EU, Brussels. Gedownload van https://ec.europa.eu/programmes/horizon2020/sites/horizon2020/ files/FactSheet_Gender_2.pdf

European Commission. (2016). She figures 2015: Gender in research and innovation. Luxembourg: Publications office of the European Union.

Galinksy, A.D., Todd, A.R., Homan, A.C., Philips, K.W., Apfelbaum, E.P., Sasaki, S.J., Richeson, J.A., Olayon, J.B., \& Maddux, W.W. (2015). Maximizing the gains and minimizing the pains of diversity: A policy perspective. Perspectives on Psychological Science, 10, $742-748$.

Gulker, J.E., Mark, A.Y., \& Monteith, M.J. (2013). Confronting prejudice: The who, what, and why of confrontation effectiveness. Social Influence, 8, 280-293.

Handley, I.M., Brown, E.R., Moss-Racusin, C.A., \& Smith, J.L. (2015). Quality of evidence revealing subtle gender biases in science is in the eye of the beholder. Proceedings of the National Academy of Sciences, 112, 13201-13206.

Homan, A.C., Buengeler, C., Eckhoff, R.A., Van Ginkel, W.P., \& Voelpel, S.C. (2015). The interplay of diversity training and diversity beliefs on team creativity in nationality diverse teams. Journal of Applied Psychology, 100, 1456-1467.

Hyde, J.S. (2014). Gender similarities and differences. Annual Review of Psychology, 65, 373398.

Kaatz, A., Gutierrez, B., \& Carnes, M. (2014). Threats to objectivity in peer review: The case of gender. Trends in Pharmacological Sciences, 35(8), 371-373.

Kaiser, C.R., Marjoe, B., Jurcevic, I., Dover, T.L., Brady, L.M., \& Shapiro, J.R. (2013). Presumed fair: Ironic effects of organizational diversity structures. Journal of Personality and Social Psychology, 104, 504-519.

Kalev, A., Dobbin, F., \& Kelly, E. (2006). Best practices or best guesses? Assessing the efficacy of corporate affirmative action and diversity policies. American Sociological Review, 71, 589-617. 
Kalinoski, Z.T., Steele-Johnson, D., Peyton, E.J., Leas, K.A., Steinke, J., \& Bowling, N. (2013). A meta-analytic evaluation of diversity training outcomes. Journal of Organizational Behavior, 34, 1076-1104.

Kawakami, K., Dovidio, J.F., \& Van Kamp, S. (2005). Kicking the habit: Effects of non-stereotypic association training and correction processes on hiring decisions. Journal of Experimental Social Psychology, 41, 68-75.

Legault, L., Gutsell, J.N., \& Inzlicht, M. (2011). Ironic effects of antiprejudice messages: How motivational interventions can reduce (but also increase) prejudice. Psychological Science, 22, 1472-1477.

Leslie, S.-J., Cimpian, A., Meyer, M., \& Freeland, E. (2015). Expectations of brilliance underlie gender distributions across academic disciplines. Science, 347, 262-265.

Leslie, L.M., Manchester, C.F., \& Dahm, P.C. (2017). Why and when does the gender gap reverse? Diversity goals and the pay premium for high potential women. Academy of Management Journal, 60, 402-432.

LNVH. (2017). LNVH Monitor Vrouwelijke Hoogleraren 2016.

Major, B., \& Kaiser, C.R. (in press). Ideology and the maintenance of group inequality. Group Processes \& Intergroup Relations.

Miller, D.I., Eagly, A.H., \& Linn, M.C. (2015). Women's representation in science predicts national gender-stereotypes: Evidence from 66 nations. Journal of Educational Psychology, 107, 631-644.

Moss-Racusin, C.A., Dovidio, J.F., Brescoll, V.L., Graham, M.J., \& Handelsman, J. (2012). Science faculty's subtle gender biases favour male students. Proceedings of the National Academy of Sciences, 109, 16474-16479.

Moss-Racusin, C.A., Molenda, A.K., \& Cramer, C.R. (2015). Can evidence impact attitudes? Public reactions to evidence of gender bias in STEM fields. Psychology of Women Quarterly, 39, 194-209.

Moss-Racusin, C.A., Van der Toorn, J., Dovidio, J.F., Brescoll, V.L., Graham, M.J., \& Handelsman, J. (2014). Scientific diversity interventions, Science, 343, 615-616.

Nature. (2014). Nature Editorial: Diversity challenge. Nature, 513, 297.

Nielsen, M.W., Alegria, S., Borjeson, L., ... \& Schiebinger, L. (2017). Gender diversity leads to better science. Proceedings of the National Academy of Sciences, 114, 1740-1742.

O'Brien, K.R., Scheffer, M., Van Nes, E.H., \& Van der Lee, R. (2015). How to break the cycle of low workforce diversity: A model for change. PLoS ONE, 10(7), e0133208.

Paluck, E.L. (2006). Diversity training and intergroup contact: A call to action research. Journal of Social Issues, 62, 577-595.

Parker, L.R., Monteith, M.J., Moss-Racusin, C.A., \& Van Camp, A.R. (2018). Promoting concern about gender bias with evidence-based confrontation. Journal of Experimental and Social Psychology, 74, 8-23.

Pronin, E., Gilovich, T., \& Ross, L. (2004). Objectivity in the eye of the beholder: Divergent perceptions of bias in self versus others. Psychological Review, 111, 781-799.

Radke, H.R.M., Hornsey, M.J., \& Barlow, F.K. (2016). Barriers to women engaging in collective action to overcome sexism. American Psychologist, 71, 863-874.

Ratcliff, R. (2015, June 10). Nobel scientist Tim Hunt: Female scientists cause trouble for men in labs. The Guardian. Gedownload op 9 mei 2018 van www.theguardian.com/ uk-news/2015/jun/10/nobel-scientist-tim-hunt-female-scientists-cause-trouble-formen-in-labs.

Roberson, L., Kulik, C., \& Pepper, M.B. (2001). Designing effective diversity training: Influence of group composition and trainee experience. Journal of Organizational Behavior, 22, 871-885. 
Ryan, M., Haslam, S.A. Hersby, M.D., Kulich, C., \& Atkins, C. (2007). Opting out or pushed off the edge? The glass cliff and the precariousness of women's leadership positions. Social and Personality Psychology Compass, 1, 266-279.

Salas, E., \& Cannon-Bowers, J.A. (2001). The science of training: A decade of progress. Annual Review of Psychology, 52, 471-499.

Sheltzer, J.M., \& Smith, J.C. (2014). Elite male faculty in the life sciences employ fewer women. Proceedings of the National Academy of Sciences, 111(28), 10107-10112.

Shen, H. (2013). Inequality quantified: Mind the gender gap. Nature, 495(7439), 22-24.

Sweetman, J., \& Barreto, M. (2016, September). The effectiveness of an online E\&D course for academics. Paper presented at the 9 th European Conference on Gender Equality in Higher Education, Paris, France.

Tannenbaum, S.I., \& Yukl, G. (1992). Training and development in work organizations. Annual Review of Psychology, 43, 399-441.

Uhlmann, E.L., \& Cohen, G.L. (2007). 'I think it, therefore it's true': Effects of self-perceived objectivity on hiring discrimination. Organizational Behavior and Human Decision Processes, 104, 207-223.

Valian, V. (1998). Why so slow: The advancement of women. Cambridge, MA: MIT Press.

Van den Brink, M. (2011). Scouting for talent: Appointment practices of women professors in academic medicine. Social Science \& Medicine, 72, 2033-2040.

Van den Brink, M., \& Benschop, Y. (2012). Gender practices in the construction of academic excellence: Sheep with five legs. Organization, 19, 507-524.

Van der Lee, R., \& Ellemers, N. (2015a). Gender contributes to personal research funding success in the Netherlands. Proceedings of the National Academy of Sciences, 112, 1234912353.

Van der Lee, R., \& Ellemers, N. (2015b). Reply to Albers: Acceptance of empirical evidence for gender disparities in Dutch research funding. Proceedings of the National Academy of Sciences, 112(50), E6830.

Van der Lee, R., \& Ellemers, N. (2015c). Reply to Volker and Steenbeek: Multiple indicators point toward gender disparities in grant funding success in The Netherlands.

Proceedings of the National Academy of Sciences, 112(51), E7038.

Van der Lee, R., \& Ellemers, N. (in press). Perceptions of gender inequality in academia: Reluctance to let go of the individual merit ideology. In B.T. Rutjens \& M.J. Brandt (Eds.), Belief systems and the perception of reality. Oxon, UK: Routledge.

Van Dijk, H., Van Engen, M.L., \& Van Knippenberg, D. (2012). Defying conventional wisdom: A meta-analytical examination of the differences between demographic and job-related diversity relationships with performance. Organizational Behavior and Human Decision Processes, 119, 38-53.

Walton, G.M. (2014). The new science of wise psychological interventions. Current Directions in Psychological Science, 23, 73-82.

Williams, W.M., \& Ceci, S.J. (2015). National hiring experiments reveal 2:1 preference for women on STEM tenure track. Proceedings of the National Academy of Sciences, 112, 5360-5365.

Williams, J.C., \& Dempsey, R. (2014). What works for women at work: Four patterns working women need to know. New York/London: New York University Press. 


\section{Characteristics and pitfalls of effective policy for gender diversity in the sciences}

R. van der Lee \& N. Ellemers, Gedrag \& Organisatie, volume 31, September 2018, nr. 3, pp. 262-280

Gender diversity is receiving considerable attention in policy interventions aimed at inclusion and equal opportunities, also in academia. Gender diversity among researchers can be beneficial for scientific progress and knowledge utilization. Yet women are still disadvantaged in all facets of academia. Even in the absence of performance differences, relevant statistics show a persistent leadership- pay, and funding gap. This is often attributed to implicit gender bias: women have less return on their academic investment and achievement than men do. Gender bias operates mostly subconsciously and the difference in opportunities for male and female scientists are often relatively small. Yet they can set in motion a self-defeating cycle where women are under-represented and are not supported, feel undervalued and become less motivated, and eventually start to disengage from work. Men as well as women often display and suffer from implicit forms of gender bias, even if it is unintentionally and is not always recognized as such. Consequently, diversity interventions are not always effective, in part because they lack sufficient support. We discuss several common traps that hinder the effectiveness of diversity interventions. In addition, we identify multiple characteristics of effective interventions. Evidence-based and context-dependent diversity interventions can foster a gender diverse academia.

Key words: diversity, gender, academia, policy, interventions 